\title{
OP-08 STATUS OF FOOD SECURITY ENTITLEMENTS ACROSS PARTICULARLY VULNERABLE TRIBAL GROUP (PVTG) POCKETS IN JHARKHAND
}

Arupa Das, Ananya Saha. Ekjut, Keonjhar (Odisha), India

10.1136/bmjgh-2016-EPHPabstracts.8

Background The Food and Agriculture Organization of the United Nations defines food security as 'a situation that exist when all people, at all times, have physical, social and economic access to sufficient, safe and nutritious food that meets their dietary needs and food preference for an active and healthy life'. In India, food security is most deficient among the tribal population, and among the Scheduled Tribes (ST) dramatically so among the Particularly Vulnerable Tribal Groups (PVTG). The latter classification, in place since 2006 when it replaced Primitive Tribal Groups, is based on attribute characteristics such as forest-based livelihood, pre-agriculture level of existence, extreme low literacy, subsistence economy, and a stagnant or declining population. Recently, the National Commission for Schedules Tribes Survey warned that food insecurity - and the government's inability to implement the 2013 Food Security Act among the PVTG - has become a threat to their mere existence. In Jharkhand, recognised PVTG are Asurs, Birhor, Birjia, Hill Kharia, Korwas, Mal Paharia, Parhaiyas, Sauria Parahia, and Savar. We studied the uptake of food security entitlements among these groups. 
Methods In coordination with the network NGOs of the Jharkhand Right to Food Campaign, we conducted a survey covering 140 PVTG households in 15 villages of 10 districts across the state. We succeeded in collecting information of 712 individuals about their entitlements under food security related government schemes and programmes.

Findings Taking a life cycle approach, we first looked at maternity entitlements. Among the PVTG under study, 67\% of pregnant women were left uncovered under the Janani Suraksha Yojna. In Jorsa, East Singhbhum district, pregnant women ware totally unaware of the Indira Gandhi Matritva Sabyog Yojna. When considering the child population, we saw that $50 \%$ of the 6 months - 3 years rarely, and $25 \%$ of the 3-6 years never visited the Anganwadi centres under the Integrated Child Development Scheme. Among children of school-going age (614 years), 62\% received Mid Day Meal service, but 21\% rarely visited and $17 \%$ never visited or had dropped out.

When looking at household food security, we found that $9 \%$ of PVTG households don't have a Targeted Public Distribution System (TPDS) ration card at all. Particularly new households, i. e. when sons get married, have difficulties in obtaining a TPDS ration card. Moreover, $50 \%$ of the potential beneficiaries do not have a job card under the Mahatma Gandhi National Rural Employment Act (MGNREGA).

Not receiving entitlements is a constant feature in all three pensions schemes: 53\% under Old, 52\% under Widow and $58 \%$ under Disabled respectively.

A prime way to avail entitlements - viz. Maternity Benefits, wages under MGNREGA, and Nation Pension Benefits - is having a bank account, which is not the case for $50 \%$ of the PVTG under study.

Discussion Over time, original forest and hill dwelling tribal communities have faced increased marginalisation. Once selfsufficient communities securing their basic means of livelihood and food from forest resources, they were deprived of these capabilities when industrialization forced them to leave their forest. Today, 42\% of PVTG are unskilled labourers without job security. Only a minority is still involved in forest-linked occupational activities: $11.4 \%$ in firewood collection, $9.2 \%$ in forest product collection, $8.5 \%$ in rope making. Income from these occupations is not sufficient to sustain their livelihood.

Article 21 of the Constitution of India grants every citizen the right to live with dignity. Article 47 of the Directive Principle of State Policy specifies the duty of the states to raise the level of nutrition and the standard of living and to improve public health. Supreme Court orders under CWP NO. 196/2001, PUCL vs. UOI - such as orders dated 2nd May 2003 and 28th November 2008 - have confirmed these duties and the consequential entitlements. In August 2013, the National Food Security Act was passed covering maternity entitlements, supplementary nutrition in Anganwadi centres, schools and TPDS. In theory, food security entitlements should have a positive impact on health and nutrition, especially of vulnerable groups. In practice, we see that these entitlements are hardly realised.

Conclusion and recommendations There is an urgent need to increase the coverage of food security amongst PVTG and ultimately uptake of entitlements. Accessibility can be improved by revising the existing policies, such as decentralizing the process of sanctioning Anganwadi centres, alternative modes of cash payment under maternity benefit, MGNREGA and pension schemes, and provision of specific permissible work under MGNREGA. Schemes and programmes can be strengthened by building infrastructure, filling vacancies, providing training, ensuring timely and adequate flow of funds, monitoring, and building strong grievance redressal mechanisms. Most importantly, government should revise the budget to increase the allocation for these schemes.

No competing interest. 